\title{
The 2011 Medical Molecular Hydrogen Symposium: An inaugural symposium of the journal Medical Gas Research
}

\author{
Shigeo Ohta ${ }^{1 *}$, Atsunori Nakao ${ }^{2}$ and Kinji Ohno ${ }^{3}$
}

\begin{abstract}
This report summarizes a brief description/history of the Hydrogen Research Meetings as well as key presentations/ oral abstracts delivered in the most recent symposium. Additionally, we introduced 38 diseases and physiological states for which hydrogen exhibits beneficial effects.
\end{abstract}

\section{Introduction}

Novel medical gases are expected to provide us with more effective therapeutic interventions and preventive medicine. In the past decades, there has been extraordinary, rapid growth in our knowledge of gaseous molecules, including nitric oxide, carbon monoxide, and hydrogen sulfide, which have been known to play important roles in biological systems. Additionally, since Dr. Shigeo Ohta's group's pioneering paper was published in the June 2007 Nature Medicine showing the potency of hydrogen as a therapeutic gas for oxidative stress-mediated diseases including cerebral infarction [1], basic and clinical hydrogen research has resurfaced. In Japan, the birthplace of hydrogen gas research, Dr. Ohta (Nippon Medical School), who is currently serving as an Associate Editor of Medical Gas Research, organized annual "Medical Molecular Hydrogen Research Meetings" in 2009 and 2010 to provide investigators with focused opportunities to share their rapid scientific progress. Most recently, we organized the Medical Molecular Hydrogen Symposium on February 18-19, 2011 at the Nagoya University Hall (Figure 1). The latest meeting is a "kick-off" inaugural meeting for the newly launched journal Medical Gas Research (MGR), which aims to promote the exchange and dissemination of the latest scientific findings.

\footnotetext{
* Correspondence: ohta@nms.ac.jp

'Department of Biochemistry and Cell Biology, Institute of Development and Aging Sciences, Graduate School of Medicine, Nippon Medical School, 1-396 Kosugi-machi, Nakahara-ku, Kawasaki-city, Kanagawa 211-8533, Japan Full list of author information is available at the end of the article
}

This report summarizes a brief description/history of the Hydrogen Research Meetings as well as key presentations/oral abstracts delivered in the most recent symposium.

\section{First Medical Molecular Hydrogen Research Meeting, 2009}

The first scientific meeting organized by Dr. Ohta was held on February 7, 2009 in Tokyo. 42 scientists and clinicians from 30 individual institutes were invited. The aim of the meeting was to unite innovative investigators to discuss and propagate medical hydrogen research. Dr. Ohta delivered the keynote presentation, in which he gave a brief history of hydrogen medicine and emphasized the huge impact of his report published in Nature Medicine. He pointed out the great interest in the field, expressed in more than 30 personal communications with investigators, and the resulting need to widen the scope of basic/clinical research to the whole world. He mentioned the successful application of hydrogen gas in a rat neonatal hypoxic brain injury model in collaboration with Dr. Xuejun Sun (Second Military Medical School, Shanghai, China) [2], who is currently serving as an Associate Editor. Dr. Atsunori Nakao (Department of Surgery, University of Pittsburgh), who is also an Associate Editor, presented the promising preliminary results of a collaborative study with Dr. Ohta's group in which hydrogen water was applied in a rat kidney transplant model. Dr. Nakao's report clearly showed survival benefits for transplant recipients. He received a research award at this meeting and his report was later published in Kidney International [3,4]. Dr. Takahisa Kawai (Forsythe Research Institute, Boston, MA, USA), who is an editorial 


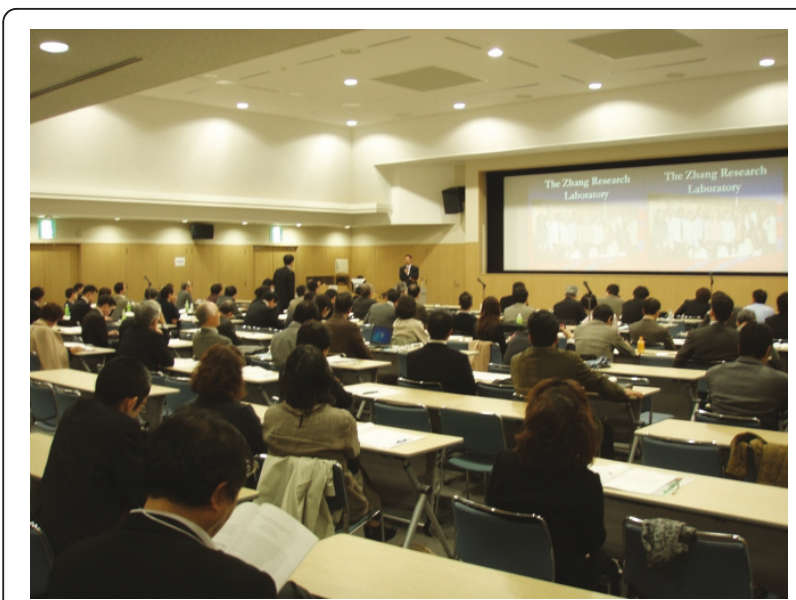

Figure $1 \mathrm{~A}$ snap shot of the Medical Molecular Hydrogen Symposium in 2011

board member, focused on hydrogen generated by intestinal bacteria. His initial studies elegantly demonstrated the critical physiological roles of gut microflora-derived hydrogen [5]. There was a general consensus that both clinicians and researchers in the field of molecular hydrogen research should gather and exchange accumulating knowledge in future annual meetings.

\section{Second Medical Molecular Hydrogen Research Meeting, 2010}

The second meeting was also organized by Dr. Ohta on February 3, 2010 in Tokyo. 47 basic scientists and clinical physicians, as well as 23 corporate participants were invited and shared the latest developments in medical issues related to hydrogen. This meeting hosted a keynote lecture, an invited lecture, two special lectures, and twelve platform presentations. After Dr. Ohta began his keynote lecture by remarking on the impressive progress over the last year, Dr. Sun gave an invited lecture and introduced the great effects of intraperitoneal administration of saline dissolved with $\mathrm{H}_{2}$ in several model animals. Dr. Takashi Asada (Department of Psychiatry, Tsukuba University), an authority on Alzheimer disease, presented the results of clinical studies involving patients with mild cognitive impairment (MCI). He started clinical intervention studies on MCI patients by orally administering hydrogen water; the project is still in progress. Dr. Toru Yoshikawa (Kaohsiung Medical University, Taiwan) also gave a special lecture on the physical aspects of hydrogen effects. He presented the physical characteristics of molecular hydrogen's interaction with water in biological systems.

\section{Third Medical Molecular Hydrogen Research Meeting, 2011}

The third meeting was organized by Dr. Kenji Ohno (Nagoya University Graduate School of Medicine), an editorial board member, and held in Nagoya on Feb 1819, 2011. This symposium mainly focused on molecular hydrogen and covered a wide-range of therapeutic gases, including hydrogen sulfide $\left(\mathrm{H}_{2} \mathrm{~S}\right)$, nitric oxide $(\mathrm{NO})$, and carbon monoxide (CO). A total of 98 academic and 53 corporate registrants attended the meeting from Japan (144), USA (5), Korea (1), and Taiwan (1). The meeting's timetable, titles, and speakers are summarized in Table 1. We also introduced 38 diseases and physiological states for which hydrogen exhibits beneficial effects (Table 2).

\section{Hydrogen}

Dr. Ohta gave a keynote lecture and introduced a number of hydrogen's potent efficacies on a broad spectrum of diseases in animal and human models, as well as the emerging molecular bases of hydrogen's effects. He emphasized the following points: (i) In the three and a half years since the first hydrogen paper was published in Nature Medicine, more than 70 original papers have been published in leading biological/medical journals. Based on cumulative knowledge, beneficial biological effects of hydrogen have been established with no doubt. (ii) There are several ways to intake or consume hydrogen, including inhaling hydrogen gas, drinking water dissolved with hydrogen (hydrogen water), taking a hydrogen bath, injecting hydrogen saline, dropping hydrogen saline into the eye, and increasing production of intestinal hydrogen by bacteria. (iii) Hydrogen shows not only anti-oxidative stress effects, but also has various anti-inflammatory and anti-allergic effects. (iv) The primary molecular target of hydrogen remains unknown. In their first report published in 2007 [1], Dr. Ohta's group indicated that cells cultured in $\mathrm{H}_{2}$-rich medium were protected against oxidative stress by the hydroxyl radical-scavenging activity of $\mathrm{H}_{2}$; however, recent evidence clearly shows that the scavenging property is not the only explanation for the potent beneficial effects of hydrogen. For example, the amount of orally administered $\mathrm{H}_{2}$ may not be enough to scavenge hydroxyl radicals. In addition, it is likely that the dwell time of $\mathrm{H}_{2}$ in the body is too short to scavenge a large amount of hydroxyl radicals that are continuously generated. (v) Several reports demonstrate an effect on the regulation of gene expressions and protein-phosphorylations; however, the transcriptional factors and kinases involved in the functions afforded by $\mathrm{H}_{2}$ have not been identified. It also remains unknown whether the regulations are directly performed by $\mathrm{H}_{2}$. (vi) The amount of administered $\mathrm{H}_{2}$ is independent of the extent of effects. Intestinal bacteria seem to produce more than 1 liter of $\mathrm{H}_{2}$ gas per day, whereas the amount of $\mathrm{H}_{2}$ originating from drinking hydrogen water is less than $50 \mathrm{ml}$. Nevertheless, additional $\mathrm{H}_{2}$ in drinking hydrogen water is 
Table 1 Scientific Program of the Medical Molecular Hydrogen Symposium in 2011

\begin{tabular}{ll}
\hline Feb. 18, 2011 & Title \\
\hline 13:00 & Opening Remarks \\
13:05 & Keynote Lecture "Recent progress towards hydrogen medicine" \\
13:35 & Scientific Session I \\
& 1. Effects of hydrogen-rich water on kidney functions in SHR.Cg-Lepr ${ }^{\text {CP } / N D m c r ~ r a t ~-~ a ~}$ \\
& metabolic syndrome model rat \\
& 2. Hydrogen-rich UW solution attenuates renal cold ischemia reperfusion injury \\
& 3. Therapeutic effect of maternal hydrogen water administration in a rat model of fetal \\
& brain damage \\
& 4. Effects of hydrogen water on human skin and hair \\
14:23 & Coffee Break \\
14:50 & Scientific Session II
\end{tabular}

Speaker

Kinji Ohno, Nagoya Univ.

Shigeo Ohta, Nippon Medical Sch.

Michio Hashimoto, Shimane Univ.

Toyofumi Abe, Osaka Univ.

Yukio Mano, Nagoya Univ.

Yoshiaki Kurita, Hosei Univ.

Ikuroh Ohsawa, Metropolitan Instittue of Gerontology

Kazutoshi Nose, National Cerebral and Cardiovascular Center

Mikio Hirayama, Kasugai Municipal

Hospital

Tohru Ibi, Aichi Medical Univ.

Tomohiro Kawamura, Univ. of Pittsburgh

9. Inhaled hydrogen gas therapy for prevention of lung transplant-induced ischemia/ reperfusion injury in rats

15:50 Invited Lecture I "Deadly gas can save a life! -Preclinical studies using carbon monoxide/hydrogen-"

Atsunori Nakao, Univ. of Pittsburgh

Break

16:30

$16: 40$

$17: 20$

18:10

Feb. 19, 2011

9:30

Invited Lecture II "Medical Gas Research"

Invited Lecture III "A hypothesis on biological protection from space radiation through the use of therapeutic gases"

Banquet
John Zhang, Loma Linda Univ.

Michael P. Schoenfeld, NASA Marshall space Flight Center

\section{$10: 30$}

$11: 10$

$11: 20$

$12: 45$

$12: 45$

\section{Symposium I "CO as a therapeutic modality"}

S1-1. Is exhaled carbon monoxide a marker of oxidative stress?

S1-2. A tracer analysis study demonstrates redistribution of endogenous carbon monoxide from blood to tissue in human body

S1-3. Translational research of carbon monoxide therapy using miniature swine

Special Lecture "Function of hydrogen sulfide and its therapeutic applications"

Break

\section{Scientific Session III}

10. Hydrogen from intestinal bacteria is protective for Con A-induced Hepatitis

11. Abnormal breath hydrogen production by ingestion of lactulose in Parkinson's disease

12. A new portable breath hydrogen analyzer and its clinical application

13. Application of hydrogen water in the dental field

Lunch

Symposium II "Biological Effects of NO"

S2-1. NO-ROS cellular signaling mediated via nitrated cyclic nucleotide

S2-2. Relationship between protein S-nitrosylation and neuronal death

S2-3. Role of nitrosative stress in chronic obstructive pulmonary disease

S2-4. Effects of simultaneous inhalation of nitric oxide and hydrogen on mouse myocardial ischemia-reperfusion injury

\section{Scientific Session 4}

14. Effect of hydrogen rich water against a progression of disease and a formation of liver tumor in NASH model mouse

15. The dynamic movement of $\mathrm{H} 2$ in a liver and its effects

16. Molecular hydrogen effectively protects cereulide-induced liver injury by suppressing apoptosis
Organizer: Atsunori Nakao, Univ. of Pittsburgh

Tohru Takahashi, Okayama Prefecture Univ.

Makoto Sawano, Saitama Medical Univ.

Hisashi Sahara, Kagoshima Univ.

Hideo Kimura, National Center of Neurology and Psychiatry

Mikihito Kajiya, The Forsyth Institute

Masaaki Hirayama, Nagoya Univ.

Akito Shimouchi, National Cerebral and Cardiovascular Center

Noriyuki Tanaka, Uchida Dental Clinic

Hirosuke Kobayashi, Kitasato Univ. Hideshi Ihara, Osaka Prefecture Univ. Takashi Uehara, Wakayama Mediccal Univ. Ryujiro Sugimoto, Iwakuni Clinical Center Hirosuke Kobayashi, Kitasato Univ.

Daisuke Kawai, Okayama Univ.

Naomi Kamimura, Nippon Medical Univ.

Sayaka Sobue, Chubu Univ.

Kinji Ohno, Nagoya Univ. 
Table 2 Thirty-eight diseases and physiological states for which hydrogen effects are reported

\begin{tabular}{|c|c|c|c|}
\hline Disease/Physiology & Species & Source of $\mathrm{H}_{2}$ & Reference \\
\hline \multicolumn{4}{|l|}{ Brain } \\
\hline Cerebral infarction & rodent & gas & {$[1]$} \\
\hline Superoxide in brain & rodent & water & {$[6]$} \\
\hline \multirow[t]{3}{*}{ Neonatal brain hypoxia } & rodent & gas & {$[2,7]$} \\
\hline & rodent & saline & {$[8]$} \\
\hline & pig & gas & [9] \\
\hline Restraint-induced dementia & rodent & water & {$[10]$} \\
\hline Alzheimer's disease & rodent & saline & {$[11]$} \\
\hline Senile dementia & rodent & water & {$[12]$} \\
\hline Parkinson's disease & rodent & water & {$[13,14]$} \\
\hline Hemorrhagic cerebral infarction & rodent & gas & {$[15]$} \\
\hline Traumatic brain injury & rodent & gas & {$[16]$} \\
\hline \multicolumn{4}{|l|}{ Spinal cord } \\
\hline Spinal cord injury & rodent & saline & {$[17]$} \\
\hline \multicolumn{4}{|l|}{ Eye } \\
\hline Glaucoma & rodent & eye drop & {$[18]$} \\
\hline Corneal alkali-burn & rodent & eye drop & {$[19]$} \\
\hline \multicolumn{4}{|l|}{ Ear } \\
\hline \multirow[t]{3}{*}{ Hearing disturbance } & rodent & medium & {$[20]$} \\
\hline & rodent & gas & {$[21]$} \\
\hline & rodent & water & {$[22]$} \\
\hline \multicolumn{4}{|l|}{ Lung } \\
\hline Lung cancer & Cells & medium & {$[23]$} \\
\hline Oxygen-induced lung injury & rodent & saline & {$[24,25]$} \\
\hline Lung transplantation & rodent & gas & {$[26]$} \\
\hline \multicolumn{4}{|l|}{ Heart } \\
\hline \multirow[t]{2}{*}{ Myocardial infarction } & rodent & gas & {$[27]$} \\
\hline & rodent & saline & {$[28]$} \\
\hline Heart transplantation & rodent & gas & {$[29]$} \\
\hline Irradiation-induced heart injury & rodent & water & {$[30]$} \\
\hline \multicolumn{4}{|l|}{ Liver } \\
\hline Hepatic ischemia & rodent & gas & {$[31]$} \\
\hline Hepatitis & rodent & bacteria & {$[5]$} \\
\hline Obstructive jaundice & rodent & saline & {$[32]$} \\
\hline \multicolumn{4}{|l|}{ Kidney } \\
\hline \multirow[t]{2}{*}{ Cisplatin nephropathy } & rodent & gas, water & [33] \\
\hline & rodent & water & {$[34]$} \\
\hline Hemodialysis & human & dialysis & {$[35,36]$} \\
\hline Kidney transplantation & rodent & water & {$[4]$} \\
\hline \multicolumn{4}{|l|}{ Pancreas } \\
\hline Acute pancreatitis & rodent & saline & {$[37]$} \\
\hline \multicolumn{4}{|l|}{ Intestine } \\
\hline \multirow[t]{2}{*}{ Intestinal graft } & rodent & gas & {$[3]$} \\
\hline & rodent & saline & {$[38,39]$} \\
\hline Ulcerative colitis & rodent & gas & {$[40]$} \\
\hline \multicolumn{4}{|l|}{ Blood vessel } \\
\hline Atherosclerosis & rodent & water & {$[41]$} \\
\hline \multicolumn{4}{|l|}{ Metabolism } \\
\hline Diabetes mellitus type 2 & human & water & {$[42]$} \\
\hline Metabolic syndrome & human & water & {$[43]$} \\
\hline Obesity/Diabetes & rodent & water & [44] \\
\hline
\end{tabular}

Table 2 Thirty-eight diseases and physiological states for which hydrogen effects are reported (Continued)

\begin{tabular}{llll}
\hline Cancer & & & \\
Tongue carcinoma & cells & medium & {$[45]$} \\
Inflammation and allergy & & & \\
Allergy type I & rodent & water & {$[46]$} \\
Sepsis & rodent & gas & {$[47]$} \\
Zymosan-induced inflammation & rodent & gas & {$[47]$} \\
Others & & & \\
Multipotent stromal cells & cells & gas & {$[48]$} \\
Radiation injury & cells & medium & {$[49,50]$} \\
\hline
\end{tabular}

Although the observations are not directly relevant to diseases, Turmeric [51] and acarbose [52] increase hydrogen production by intestinal bacteria in humans.

unambiguously effective. Many mysteries of hydrogen therapy remain unsolved. He closed his talk by emphasizing that the molecular mechanisms underlying the amazing effects of a very small amount of $\mathrm{H}_{2}$ remain elusive.

Sixteen platform speakers presented clinical and basic aspects of the medical application of molecular hydrogen. Among them were three treatments for patients with neurological and dental diseases. Dr. Mikio Hirayama (Department of Neurology, Kasugai City Hospital) and his colleagues presented their clinical report of treatment for a patient with mitochondrial encephalomyopathy, lactic acidosis, and stroke-like episode (MELAS) syndrome. He reported that a 33-year-old female patient was successfully treated by drinking hydrogen-containing water for one and half years, which reduced the frequency of episodic cerebral ischemia. Dr. Tohru Ibi (Department of Neurology, Aichi Medical School) conducted an open label trial on mitochondrial disorders and inflammatory myopathies, and demonstrated a remarkable reduction of several serum markers specific for myelopathy. He also conducted a doubleblind crossover trial; however, the trial showed no significant effects, which was likely due to a small amount of hydrogen water and to a short observation period. Both reports suggest that oral administration of hydrogen water is likely to be effective for mitochondrial diseases. Dr. Noriyuki Tanaka (Uchida Dental Clinic) reported that direct dental application of hydrogen water on injured regions reduced inflammation and promoted healing in dental operations, including tooth extraction.

Medical Gas Research's editor-in-chief Dr. John Zhang (Department of Neurosurgery, Loma Linda University, CA) gave a greeting talk, introducing the aims and scope of the journal. Dr. Zhang pointed out the importance of stimulating medical gas research and collaborating with a wide-range of people in various fields. 
Dr. Michael P. Schoenfeld from NASA gave a special lecture on the potential application of $\mathrm{H}_{2}$ to protect astronauts from radiation-mediated injury during long space travel. Cosmic radiation induces serious oxidative stress, which is one of the major issues to be resolved by hydrogen research.

\section{Other Medical Gases (NO, CO, and $\mathrm{H}_{2} \mathrm{~S}$ )}

Mammals produce $\mathrm{NO}, \mathrm{CO}$, and $\mathrm{H}_{2} \mathrm{~S}$ by their native enzymes; however, mammals lack an enzyme to produce $\mathrm{H}_{2}$. All four gases modulate signaling pathways and have some therapeutic effects. Thus, we invited leading $\mathrm{NO}, \mathrm{CO}$, and $\mathrm{H}_{2} \mathrm{~S}$ researchers to the symposium.

Dr. Hideo Kimura (National Center of Neurology and Psychiatry), an editorial board member, gave a special lecture on hydrogen sulfide $\left(\mathrm{H}_{2} \mathrm{~S}\right)$. Dr. Kimura discovered biological roles for $\mathrm{H}_{2} \mathrm{~S}$. He reviewed studies on $\mathrm{H}_{2} \mathrm{~S}$ from past to present and emphasized the potential for actual medical applications.

Dr. Nakao organized a mini-symposium on carbon monoxide $(\mathrm{CO})$. In the mini-symposium, the discrepancy between the animal and human models was discussed. CO binds to human hemoglobin more strongly than to murine hemoglobin; this seems to be the reason why $\mathrm{CO}$ is more toxic in clinical studies.

Dr. Hirosuke Kobayashi (Department of Respiratory Medicine, Kitasato University), an editorial board member, organized a mini-symposium on nitric oxide (NO). Dr. Kobayashi explained the contradictory properties of NO; while it is medically beneficial, it is also toxic and enhances oxidative stress. NO has been approved as a therapeutic agent in clinical practice. He presented the amazing effects of inhaling an $\mathrm{NO}$ and $\mathrm{H}_{2}$ mixture. $\mathrm{NO}$ enhances oxidative stress and induces production of peroxynitrite, and $\mathrm{H}_{2}$ reduces peroxynitrite derived from NO. Indeed, he presented that the mixture of NO and $\mathrm{H}_{2}$ improves the number of surviving myocytes in a rodent model of myocardial infarction. The mixture of $\mathrm{NO}$ and $\mathrm{H}_{2}$ may be a promising modality for clinical applications.

In addition to $\mathrm{NO}, \mathrm{CO}$, and $\mathrm{H}_{2} \mathrm{~S}$, Dr. Zhang addressed potential effects of inhaled xeon and helium in animal models in his invited lecture.

\section{Commercial products}

Six companies financially supported the meeting by demonstrating their new commercial products. Melodian Co Ltd. presented a sports drink containing $\mathrm{H}_{2}$, and Miz Co Ltd. introduced an interesting device to prepare a clinically applicable $\mathrm{H}_{2}$-rich infusion solution by simply soaking an infusion bag in hydrogen water. With this method, no other treatment is necessary to prepare hydrogen infusion solution without opening the infusion bag. Taiyo Co Ltd. presented reasonably priced devices to measure $\mathrm{H}_{2}$ gas in breath. Takaoka Co Ltd. demonstrated a tiny home apparatus to produce hydrogen water. Doctor's Choice Co Ltd. demonstrated powders to prepare a hydrogen bath at home using a new material that releases $\mathrm{H}_{2}$ gas. These new products will help expand our knowledge and applicability of hydrogen research.

\section{Acknowledgements}

We would like to express our sincere thanks to all the meeting participants and staff, especially Dr. Mikako Ito at Nagoya University, who conducted the meeting.

\section{Author details}

${ }^{1}$ Department of Biochemistry and Cell Biology, Institute of Development and Aging Sciences, Graduate School of Medicine, Nippon Medical School, 1-396 Kosugi-machi, Nakahara-ku, Kawasaki-city, Kanagawa 211-8533, Japan.

${ }^{2}$ Thomas E Starzl Transplantation Institute, Department of Surgery, University of Pittsburgh Medical Center, 200 Lothrop Street, Pittsburgh, PA 15213, USA. ${ }^{3}$ Division of Neurogenetics, Center for Neurological Diseases and Cancer, Nagoya University Graduate School of Medicine, 65 Tsurumai, Showa-ku, Nagoya 466-8550, Japan.

Received: 9 March 2011 Accepted: 7 June 2011 Published: 7 June 2011

\section{References}

1. Ohsawa I, Ishikawa M, Takahashi K, Watanabe M, Nishimaki K, Yamagata K, Katsura K, Katayama Y, Asoh S, Ohta S: Hydrogen acts as a therapeutic antioxidant by selectively reducing cytotoxic oxygen radicals. Nat Med 2007, 13:688-694.

2. Cai J, Kang Z, Liu WW, Luo X, Qiang S, Zhang JH, Ohta S, Sun X, Xu W, Tao H, Li R: Hydrogen therapy reduces apoptosis in neonatal hypoxiaischemia rat model. Neurosci Lett 2008, 441:167-172.

3. Buchholz BM, Kaczorowski DJ, Sugimoto R, Yang R, Wang Y, Billiar TR, McCurry KR, Bauer AJ, Nakao A: Hydrogen inhalation ameliorates oxidative stress in transplantation induced intestinal graft injury. Am J Transplant 2008, 8:2015-2024.

4. Cardinal JS, Zhan JH, Wang YN, Sugimoto R, Tsung A, McCurry KR, Billiar TR, Nakao A: Oral hydrogen water prevents chronic allograft nephropathy in rats. Kidney Int 2010, 77:101-109.

5. Kajiya M, Sato K, Silva MJ, Ouhara K, Do PM, Shanmugam KT, Kawai T: Hydrogen from intestinal bacteria is protective for Concanavalin Ainduced hepatitis. Biochem Biophys Res Commun 2009, 386:316-321.

6. Sato Y, Kajiyama S, Amano A, Kondo Y, Sasaki T, Handa S, Takahashi R, Fukui M, Hasegawa G, Nakamura N, et al: Hydrogen-rich pure water prevents superoxide formation in brain slices of vitamin C-depleted SMP30/GNL knockout mice. Biochem Biophys Res Commun 2008, 375:346-350.

7. Matchett GA, Fathali N, Hasegawa Y, Jadhav V, Ostrowski RP, Martin RD, Dorotta IR, Sun $\mathrm{X}$, Zhang $\mathrm{JH}$ : Hydrogen gas is ineffective in moderate and severe neonatal hypoxia-ischemia rat models. Brain Res 2009, 1259:90-97.

8. Cai JM, Kang ZM, Liu K, Liu WW, Li RP, Zhang JH, Luo X, Sun XJ: Neuroprotective effects of hydrogen saline in neonatal hypoxia-ischemia rat model. Brain Res 2009, 1256:129-137.

9. Domoki F, Olah O, Zimmermann A, Nemeth I, Toth-Szuki V, Hugyecz M, Temesvari P, Bart F: Hydrogen is Neuroprotective and Preserves Cerebrovascular Reactivity in Asphyxiated Newborn Pigs. Pediatr Res 2010, 68:387-392.

10. Nagata K, Nakashima-Kamimura N, Mikami T, Ohsawa I, Ohta S: Consumption of Molecular Hydrogen Prevents the Stress-Induced Impairments in Hippocampus-Dependent Learning Tasks during Chronic Physical Restraint in Mice. Neuropsychopharmacology 2009, 34:501-508.

11. Li J, Wang C, Zhang JH, Cai JM, Cao YP, Sun XJ: Hydrogen-rich saline improves memory function in a rat model of amyloid-beta-induced Alzheimer's disease by reduction of oxidative stress. Brain Res 2010, 1328:152-161.

12. Gu Y, Huang CS, Inoue T, Yamashita T, Ishida T, Kang KM, Nakao A: Drinking Hydrogen Water Ameliorated Cognitive Impairment in 
Senescence-Accelerated Mice. Journal of Clinical Biochemistry and Nutrition 2010, 46:269-276.

13. Fu Y, Ito M, Fujita $Y$, Ito M, Ichihara M, Masuda A, Suzuki Y, Maesawa S, Kajita $Y$, Hirayama $M$, et al: Molecular hydrogen is protective against 6hydroxydopamine-induced nigrostriatal degeneration in a rat model of Parkinson's disease. Neurosci Lett 2009, 453:81-85.

14. Fujita K, Seike T, Yutsudo N, Ohno M, Yamada H, Yamaguchi H, Sakumi K, Yamakawa Y, Kido MA, Takaki A, et al: Hydrogen in drinking water reduces dopaminergic neuronal loss in the 1-methyl-4-phenyl-1,2,3,6tetrahydropyridine mouse model of Parkinson's disease. PLOS One 2009, 4:e7247.

15. Chen CH, Manaenko A, Zhan Y, Liu WW, Ostrowki RP, Tang J, Zhang JH: Hydrogen Gas Reduced Acute Hyperglycemia-Enhanced Hemorrhagic Transformation In A Focal Ischemia Rat Model. Neuroscience 2010, 169:402-414.

16. Ji XT, Liu WB, Xie KL, Liu WP, Qu Y, Chao XD, Chen T, Zhou J, Fei Z: Beneficial effects of hydrogen gas in a rat model of traumatic brain injury via reducing oxidative stress. Brain Res 2010, 1354:196-205.

17. Chen CW, Chen QB, Mao YF, Xu SM, Xia CY, Shi XY, Zhang JH, Yuan HB, Sun XJ: Hydrogen-Rich Saline Protects Against Spinal Cord Injury in Rats. Neurochem Res 2010, 35:1111-1118.

18. Oharazawa $H$, Igarashi T, Yokota T, Fujii H, Suzuki H, Machide M, Takahashi H, Ohta S, Ohsawa I: Protection of the Retina by Rapid Diffusion of Hydrogen: Administration of Hydrogen-Loaded Eye Drops in Retinal Ischemia-Reperfusion Injury. Invest Ophthalmol Vis Sci 2010, 51:487-492.

19. Kubota M, Shimmura S, Kubota S, Miyashita H, Kato N, Noda K, Ozawa Y, Usui T, Ishida S, Umezawa K, Kurihara T, Tsubota K: Hydrogen and Nacetyl-L-cysteine rescue oxidative stress-induced angiogenesis in a mouse corneal alkali-burn model. Invest Ophthalmol Vis Sci 2011, 52:427-433.

20. Kikkawa YS, Nakagawa T, Horie RT, Ito J: Hydrogen protects auditory hair cells from free radicals. Neuroreport 2009, 20:689-694.

21. Taura A, Kikkawa YS, Nakagawa T, Ito J: Hydrogen protects vestibular hair cells from free radicals. Acta Otolaryngol (Stockh) 2010, 130:95-100.

22. Lin Y, Kashio A, Sakamoto T, Suzukawa K, Kakigi A, Yamasoba T: Hydrogen in drinking water attenuates noise-induced hearing loss in guinea pigs. Neurosci Lett 2011, 487:12-16.

23. Ye J, Li Y, Hamasaki T, Nakamichi N, Komatsu T, Kashiwagi T, Teruya K, Nishikawa R, Kawahara T, Osada K, et al: Inhibitory effect of electrolyzed reduced water on tumor angiogenesis. Biological \& Pharmaceutical Bulletin 2008, 31:19-26.

24. Zheng J, Liu K, Kang ZM, Cai JM, Liu WW, Xu WG, Li RP, Tao HY, Zhang JH, Sun XJ: Saturated hydrogen saline protects the lung against oxygen toxicity. Undersea Hyperb Med 2010, 37:185-192.

25. Sun QA, Cai JM, Liu SL, Liu Y, Xu WG, Tao HY, Sun XJ: Hydrogen-Rich Saline Provides Protection Against Hyperoxic Lung Injury. J Surg Res 2011, 165:E43-E49.

26. Kawamura T, Huang CS, Tochigi N, Lee S, Shigemura N, Billiar TR, Okumura M, Nakao A, Toyoda Y: Inhaled Hydrogen Gas Therapy for Prevention of Lung Transplant-Induced Ischemia/Reperfusion Injury in Rats. Transplantation 2010, 90:1344-1351.

27. Hayashida K, Sano M, Ohsawa I, Shinmura K, Tamaki K, Kimura K, Endo J, Katayama T, Kawamura A, Kohsaka $\mathrm{S}$, et al: Inhalation of hydrogen gas reduces infarct size in the rat model of myocardial ischemia-reperfusion injury. Biochem Biophys Res Commun 2008, 373:30-35.

28. Sun Q, Kang ZM, Cai JM, Liu WW, Liu Y, Zhang JH, Denoble PJ, Tao HY, Sun XJ: Hydrogen-Rich Saline Protects Myocardium Against Ischemia/ Reperfusion Injury in Rats. Exp Biol Med 2009, 234:1212-1219.

29. Nakao A, Kaczorowski DJ, Wang YN, Cardinal JS, Buchholz BM, Sugimoto R, Tobita K, Lee S, Toyoda Y, Billiar TR, McCurry KR: Amelioration of rat cardiac cold ischemia/reperfusion injury with inhaled hydrogen or carbon monoxide, or both. J Heart Lung Transplant 2010, 29:544-553.

30. Qian LR, Cao F, Cui JG, Wang YC, Huang YC, Chuai YH, Zaho LQ, Jiang H, Cai JM: The Potential Cardioprotective Effects of Hydrogen in Irradiated Mice. J Radiat Res (Tokyo) 2010, 51:741-747.

31. Fukuda K, Asoh S, Ishikawa M, Yamamoto Y, Ohsawa I, Ohta S: Inhalation of hydrogen gas suppresses hepatic injury caused by ischemia/ reperfusion through reducing oxidative stress. Biochem Biophys Res Commun 2007, 361:670-674.
32. Liu Q, Shen WF, Sun HY, Fan DF, Nakao A, Cai JM, Yan G, Zhou WP, Shen RX, Yang JM, Sun XJ: Hydrogen-rich saline protects against liver injury in rats with obstructive jaundice. Liver International 2010, 30:958-968.

33. Nakashima-Kamimura N, Mori T, Ohsawa I, Asoh S, Ohta S: Molecular hydrogen alleviates nephrotoxicity induced by an anti-cancer drug cisplatin without compromising anti-tumor activity in mice. Cancer Chemother Pharmacol 2009.

34. Kitamura A, Kobayashi S, Matsushita T, Fujinawa H, Murase K: Experimental verification of protective effect of hydrogen-rich water against cisplatininduced nephrotoxicity in rats using dynamic contrast-enhanced $\mathrm{CT}$. Br J Radiol 2010, 83:509-514.

35. Nakayama M, Kabayama S, Nakano H, Zhu WJ, Terawaki H, Nakayama K, Katoh K, Satoh T, Ito S: Biological Effects of Electrolyzed Water in Hemodialysis. Nephron Clinical Practice 2009, 112:C9-C15.

36. Nakayama M, Nakano H, Hamada H, Itami N, Nakazawa R, Ito S: A novel bioactive haemodialysis system using dissolved dihydrogen $(\mathrm{H}-2)$ produced by water electrolysis: a clinical trial. Nephrology Dialysis Transplantation 2010, 25:3026-3033.

37. Chen $H$, Sun YP, Li Y, Liu WW, Xiang HG, Fan LY, Sun Q, Xu XY, Cai JM, Ruan $\mathrm{CP}$, et al: Hydrogen-rich saline ameliorates the severity of Larginine-induced acute pancreatitis in rats. Biochem Biophys Res Commun 2010, 393:308-313.

38. Mao YF, Zheng XF, Cai JM, You XM, Deng XM, Zhang JH, Jiang L, Sun XJ: Hydrogen-rich saline reduces lung injury induced by intestinal ischemia/ reperfusion in rats. Biochem Biophys Res Commun 2009, 381:602-605.

39. Zheng X, Mao Y, Cai J, Li Y, Liu W, Sun P, Zhang JH, Sun X, Yuan H: Hydrogen-rich saline protects against intestinal ischemia/reperfusion injury in rats. Free Radic Res 2009, 43:478-484.

40. Kajiya M, Silva MJ, Sato K, Ouhara K, Kawai T: Hydrogen mediates suppression of colon inflammation induced by dextran sodium sulfate. Biochem Biophys Res Commun 2009, 386:11-15.

41. Ohsawa I, Nishimaki K, Yamagata K, Ishikawa M, Ohta S: Consumption of hydrogen water prevents atherosclerosis in apoliporotein $\mathrm{E}$ knockout mice. Biochem Biophys Res Commun 2008, 377:1195-1198.

42. Kajiyama S, Hasegawa G, Asano M, Hosoda H, Fukui M, Nakamura N, Kitawaki J, Imai S, Nakano K, Ohta M, et al: Supplementation of hydrogenrich water improves lipid and glucose metabolism in patients with type 2 diabetes or impaired glucose tolerance. Nutrition Research 2008, 28:137-143.

43. Nakao A, Toyoda Y, Sharma P, Evans M, Guthrie N: Effectiveness of Hydrogen Rich Water on Antioxidant Status of Subjects with Potential Metabolic Syndrome-An Open Label Pilot Study. Journal of Clinical Biochemistry and Nutrition 2010, 46:140-149.

44. Kamimura N, Nishimaki K, Ohsawa I, Ohta S: Molecular Hydrogen Improves Obesity and Diabetes by Inducing Hepatic FGF21 and Stimulating Energy Metabolism in db/db Mice. Obesity 2011.

45. Saitoh Y, Okayasu H, Xiao L, Harata Y, Miwa N: Neutral pH hydrogenenriched electrolyzed water achieves tumor-preferential clonal growth inhibition over normal cells and tumor invasion inhibition concurrently with intracellular oxidant repression. Oncol Res 2008, 17:247-255.

46. Itoh T, Fujita Y, Ito M, Masuda A, Ohno K, Ichihara M, Kojima T, Nozawa Y, Ito M: Molecular hydrogen suppresses FcepsilonRl-mediated signal transduction and prevents degranulation of mast cells. Biochem Biophys Res Commun 2009, 389:651-656.

47. Xie KL, Yu YH, Pei YP, Hou LC, Chen SY, Xiong LZ, Wang GL: Protective effects of hydrogen gas on murine polymicrobial sepsis via reducing oxidative stress and hmgb1 release. Shock 2010, 34:90-97.

48. Kawasaki H, Guan JJ, Tamama K: Hydrogen gas treatment prolongs replicative lifespan of bone marrow multipotential stromal cells in vitro while preserving differentiation and paracrine potentials. Biochem Biophys Res Commun 2010, 397:608-613.

49. Qian LR, Cao F, Cui JG, Huang YC, Zhou XJ, Liu SL, Cai JM: Radioprotective effect of hydrogen in cultured cells and mice. Free Radic Res 2010, 44:275-282.

50. Qian LR, Li BL, Cao F, Huang YC, Liu SL, Cai JM, Gao F: Hydrogen-rich pbs protects cultured human cells from ionizing radiation-induced cellular damage. Nuclear Technology \& Radiation Protection 2010, 25:23-29.

51. Shimouchi A, Nose K, Takaoka M, Hayashi H, Kondo T: Effect of Dietary Turmeric on Breath Hydrogen. Dig Dis Sci 2009, 54:1725-1729. 
52. Suzuki Y, Sano M, Hayashida K, Ohsawa I, Ohta S, Fukuda K: Are the effects of alpha-glucosidase inhibitors on cardiovascular events related to elevated levels of hydrogen gas in the gastrointestinal tract? FEBS Lett 2009, 583:2157-2159.

doi:10.1186/2045-9912-1-10

Cite this article as: Ohta et al:: The 2011 Medical Molecular Hydrogen Symposium: An inaugural symposium of the journal Medical Gas Research. Medical Gas Research 2011 1:10.

Submit your next manuscript to BioMed Central and take full advantage of:

- Convenient online submission

- Thorough peer review

- No space constraints or color figure charges

- Immediate publication on acceptance

- Inclusion in PubMed, CAS, Scopus and Google Scholar

- Research which is freely available for redistribution

Submit your manuscript at www.biomedcentral.com/submit
() Biomed Central 